Article

\title{
Supercritical Technology-Based Date Sugar Powder Production: Process Modeling and Simulation
}

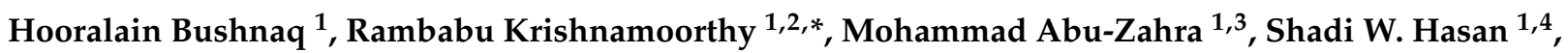 \\ Hanifa Taher ${ }^{1}$, Suliman Yousef Alomar ${ }^{5} \mathbb{D}$, Naushad Ahmad ${ }^{6}$ and Fawzi Banat ${ }^{1, *}$ (D) \\ 1 Department of Chemical Engineering, Khalifa University of Science and Technology, \\ Abu Dhabi 127788, United Arab Emirates; 100052972@ku.ac.ae (H.B.); \\ mohammad.abuzahra@ku.ac.ae (M.A.-Z.); shadi.hasan@ku.ac.ae (S.W.H.); hanifa.alblooshi@ku.ac.ae (H.T.) \\ 2 Tata Consultancy Services, Bletchley, Milton Keynes, Buckinghamshire MK3 5JL, UK \\ 3 Research and Innovation Center on $\mathrm{CO}_{2}$ and Hydrogen (RICH Center), Khalifa University of Science \\ and Technology, Abu Dhabi 127788, United Arab Emirates \\ 4 Center for Membranes and Advanced Water Technology (CMAT), Khalifa University of Science and \\ Technology, Abu Dhabi 127788, United Arab Emirates \\ 5 Zoology Department, King Saud University, Riyadh 11451, Saudi Arabia; syalomar@ksu.edu.sa \\ 6 Chemistry Department, College of Science, King Saud University, Riyadh 11451, Saudi Arabia; \\ anaushad@ksu.edu.sa \\ * Correspondence: rambabu.krishnamoorthy@ku.ac.ae (R.K.); fawzi.banat@ku.ac.ae (F.B.)
}

Citation: Bushnaq, H.;

Krishnamoorthy, R.; Abu-Zahra, M.;

Hasan, S.W.; Taher, H.; Alomar, S.Y.;

Ahmad, N.; Banat, F. Supercritical

Technology-Based Date Sugar

Powder Production: Process

Modeling and Simulation. Processes

2022, 10, 257. https://doi.org/

$10.3390 /$ pr10020257

Academic Editors: Maria Angela

A. Meireles, Ádina L. Santana and

Grazielle Nathia Neves

Received: 5 January 2022

Accepted: 18 January 2022

Published: 27 January 2022

Publisher's Note: MDPI stays neutral with regard to jurisdictional claims in published maps and institutional affiliations.

Copyright: (C) 2022 by the authors. Licensee MDPI, Basel, Switzerland. This article is an open access article distributed under the terms and conditions of the Creative Commons Attribution (CC BY) license (https:// creativecommons.org/licenses/by/ $4.0 /)$.

\begin{abstract}
Date palm fruits (Phoenix dactylifera) contain high levels of fructose and glucose sugars These natural sugar forms are healthy, nutritional and easily assimilate into human metabolism. The successful production of soluble date sugar powder from nutritious date fruits would result in a new food product that could replace the commercial refined sugar. In this work, a novel process technology based on the supercritical extraction of sugar components from date pulp was modeled and simulated using Aspen Plus software. The process model consisted of three main steps that were individually simulated for their optimal working conditions as follows: (a) freeze-drying of the date pulp at $-42{ }^{\circ} \mathrm{C}$ and 0.0001 bar; (b) supercritical extraction of the sugar components using a $6.77 \mathrm{wt} . \%$ water mixed $\mathrm{CO}_{2}$ solvent system at a pressure of $308 \mathrm{bar}$, temperature of $65^{\circ} \mathrm{C}$, and $\mathrm{CO}_{2}$ flow rate of $31,000 \mathrm{~kg} / \mathrm{h}$; and (c) spray-drying of the extract using $40 \mathrm{wt} . \%$ Gum Arabic as the carrier agent and air as drying medium at $150{ }^{\circ} \mathrm{C}$. The overall production yield of the process showed an extraction efficiency of $99.1 \%$ for the recovery of total reducing sugars from the date fruit. The solubility of the as-produced date sugar powder was improved by the process selectivity, elimination of insoluble fiber contents, and the addition of Gum Arabic. The solubility of the final date sugar product was estimated as $0.89 \mathrm{~g} / \mathrm{g}$ water.
\end{abstract}

Keywords: date sugar production; freeze-drying; supercritical extraction; spray-drying; process simulation; aspen plus

\section{Introduction}

Recently, the increasing awareness of the health effects of refined sugar has shifted consumers' focus towards natural and organic sugars. This has provided a tremendous scope for the global organic sugar market, which is expected to grow by $14 \%$ between 2019 and 2027 for a net worth of USD 4500 million by 2027 [1]. To meet the growing demands for organic sugar, a wide variety of plant sources and their products are being analyzed for the development of natural fruit-sugar products that benefit human health. Among them, date palm (Phoenix dactylifera) is a promising plant widely cultivated in the arid regions of the Persian Gulf and North Africa [2]. Date palm fruits contain high amounts of fructose and glucose sugars with very little sucrose content [3]. These natural sugar forms are simple, healthy, and assimilate easily into human metabolism. The fruit contains 
numerous health benefits, including nutritional, functional, and therapeutic values [4]. Date sugar is commercially produced in syrup form through a hot water extraction method. However, there are various drawbacks associated with this method, such as low extraction performance, high energy input, and degradation of thermolabile compounds [5].

Recovery of sugar components from the date fruit biomatrix is mainly hindered by the tough skin and gummy consistency of the fruit pulp. Moreover, the rigid cell membrane layers of the biomatrix retard the movement of solvent in and out of the plant cells. As a result, most of the valuable sugar components are lost with spent biomass in the conventional hot water extraction process, decreasing the extraction efficiency [6]. Thus, an innovative process technology is required to overcome these limitations and efficiently recover the sugar components from date fruits. Non-conventional techniques such as microwave-, ultrasonic-, supercritical-, enzymatic-, and magnetic-/electrical- assisted extraction are widely explored for the effective extraction of various bioactive compounds from different plants and their parts [7]. These advanced approaches are advantageous because they are less costly to operate, require a shorter treatment time, consume low amounts of energy, and do not produce any toxic byproducts.

Compared to other non-conventional extraction techniques, supercritical $\mathrm{CO}_{2}\left(\mathrm{Sc}-\mathrm{CO}_{2}\right)$ extraction has gained increased popularity due to its sustainability, versatility, and absence of solvent contamination [8]. Due to the properties that can be readily modified with changes in pressure and temperature, supercritical fluids have a wide range of applications. Indeed, the properties of both liquid and gaseous matter are combined in the supercritical phase [9]. One of the notable benefits of supercritical solvent-based extraction is that the solvent can be fully separated from the desired solutes, thus ensuring product purity. Various studies have investigated the extraction of high-value components from fruits and vegetable tissues using supercritical fluids, specifically $\mathrm{Sc}-\mathrm{CO}_{2}$ [9-12]. However, usage of $\mathrm{Sc}-\mathrm{CO}_{2}$ for plant carbohydrates extraction is partly hampered by its low polarity, which limits the solubilization of the targeted compounds into $\mathrm{Sc}-\mathrm{CO}_{2}$. To overcome this problem, high-density polar solvents are used as a co-solvent to enhance the solubility of polar sugars in $\mathrm{Sc}-\mathrm{CO}_{2}$. Studies on carbohydrate solubility in $\mathrm{Sc}-\mathrm{CO}_{2}$ have shown that using polar co-solvents such as water significantly improves the solubility and separation of carbohydrates from mixtures at an optimal concentration of the co-solvent [13].

Further, a pre-drying step of the date pulp (prior to supercritical extraction) is essential for the maximum recovery of sugars and other nutritive analytes from the fruit matrix. Among the different pre-drying methods that could be applied to produce dehydrated food, freeze-drying is recognized as one of the best drying techniques to preserve food quality [14-16]. Freeze-drying, also known as lyophilization, is the process of removing water from the food by an initial freezing phase followed by a sublimation phase to remove the ice as vapor. The removal of water from food by sublimation protects the food product against the loss of essential components and damage caused by chemical reactions associated with the withdrawal or vaporization of liquid water [17].

A post-drying stage of the extract (obtained from the $\mathrm{Sc}-\mathrm{CO}_{2}$ extraction) to a solid powder form ensures product stability and longevity of the sugar. The surface area of the final date sugar product plays a vital role in determining its dissolution rate. Spray-drying is one of the most widely used solvent evaporation techniques in the food industry to obtain products with a large surface area $[18,19]$. However, the rubbery nature of the low molecular weight sugars in the extract (owing to their lower transition temperature) causes product instability and particle agglomeration during the drying process. Hence, a carrier agent is highly required in the post-drying step to overcome these limitations. Gum Arabic (GA) is a widely studied carrier agent due to its low viscosity and high solubility [18]. It is a natural prebiotic and is considered natural, edible, and a safe source of dietary fiber [20]. GA is a complex polysaccharide that benefits gut health, digestion, and cardiovascular health.

A careful evaluation of the scientific literature shows that freeze-drying and spraydrying are the best drying techniques for the pre- and post-drying stages of the main extraction [14,21]. Hence, the same methods were adopted in this study to develop a 
novel process technology based on $\mathrm{Sc}-\mathrm{CO}_{2}$ extraction for the enhanced recovery and production of soluble date sugar powder from the date fruit. Based on these literature findings, an Integrated Date Sugar Production Process (IDSPP) involving three main stages is conceptualized as follows: (i) Freeze-drying of date pulp, (ii) $\mathrm{Sc}-\mathrm{CO}_{2}$-assisted extraction of date syrup with water as a co-solvent [8], and (iii) spray-drying of the extract for the production of soluble powder date sugar.

This study focuses on the modeling and simulation of the IDSPP process using Aspen Steady-State Modeler software to establish the feasibility of the process and determine the optimum working conditions for the process to maximize the sugar yield of date fruits. The simulation results would provide the necessary process data for the new technology and the recommended values for various critical process parameters for the experimental development and realization of the IDSPP process. Continuous-model simulation was performed for each stage of the process as a discrete block to determine the optimal values of the critical operating parameters for the respective stage of the IDSPP plant.

\section{Materials and Methods}

\subsection{IDSPP Flowsheet}

The process flowsheet for the as-proposed IDSPP technology is shown in Figure 1. Freeze-drying, supercritical extraction, and spray-drying are the major unit operations in the process. Operating pressure, freezing temperature, and drying temperature are the main parameters examined for the freeze-drying (FD) stage to minimize the moisture content in the fruit. Regarding the supercritical extraction (SCE) stage, variables such as operating pressure, temperature, and solvent:co-solvent ratio were considered to optimize the extraction efficiency. For the final spray-drying (SD) stage, the mass flow rate and temperature of air (drying medium), and feed flow rate were studied to understand their effects on the size and solubility of the final date sugar product.

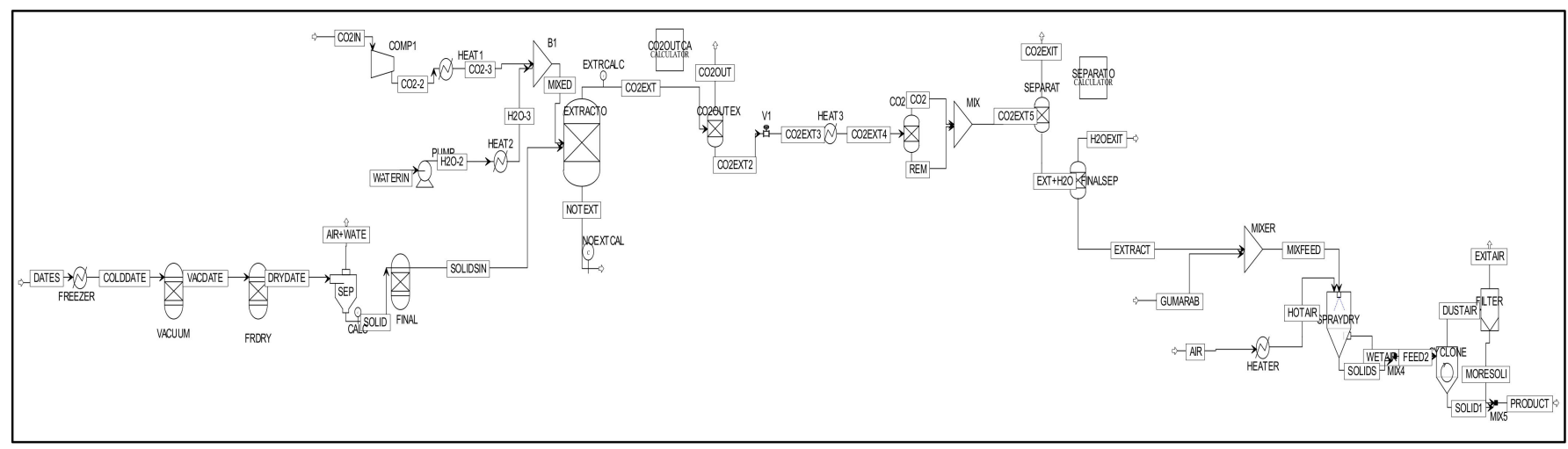

Figure 1. Integrated Date Sugar Production Process (IDSPP) flow diagram.

\subsection{Materials}

The lack of experimental data for the IDSPP at its design stage creates greater reliability on numerical simulation to provide useful information for the process. Commercial process simulation software, Aspen Plus V10 (2019), was used to solve the flowsheets encountered in this work. The software was used to understand the compositions of various phases and streams involved in each stage of the IDSPP. The simulations were run on a standalone personal computer (PC) using a Microsoft Windows 10 (2020) operating system.

\subsection{Data}

The essential properties and data for the Barhe variant of the date palm fruits were obtained from a study conducted by Rambabu et al., [2]. The properties (Table S1, Supplementary Materials) and structure of the GA (Figure S1, Supplementary Materials) were included in the Aspen database through the user interface [22]. The necessary user- 
defined functions (UDFs) pertaining to the solubility behavior of the analytes into the $\mathrm{Sc}-\mathrm{CO}_{2}$ /water system (for the extraction stage) were developed using Phyton (V 3.9.9) scripting and patched to Aspen software.

\subsection{Method}

The simulation was performed through a model-based representation of chemical, physical, biological, and technical processes and unit operations in the software. The simulation prerequisites involved a detailed understanding of the chemical and physical properties of pure components and mixtures of various streams, as well as mathematical models that allowed stoichiometry-based process calculations. The simulator described processes in flow diagrams where the unit operations are positioned and connected by streams. The solver computed the necessary mass and energy balances for each node to find a stable operating point. The thermodynamic model suitable to present the behavior of each participating phase was selected after careful analysis of a wide range of scientific literature.

For the modeling, a basis of $100 \mathrm{~kg} / \mathrm{h}$ of date fruit pulp, including the moisture content, was selected. All necessary components were found and defined in the Aspen database except for the date fruit, that was specified as a non-conventional solid. The date fruit was specified using the HCOALGEN enthalpy model and the DCHARIGT density model. Electrolyte Wizard was selected for the ice formation and drying of water, and the ice formation reaction was chosen and added to the chemistry profile to be used as an input to the units involving water phase change [23]. The Particle Size Distribution (PSD) was defined to describe the appearance of the non-conventional substream. A log-normal distribution function was used to describe the PSD with a geometric mean deviation of $27.5 \mathrm{~mm}$, and a mass median diameter $\left(D_{50}\right)$ value of $27.5 \mathrm{~mm}$. The IDEAL property method was selected that accommodates both Raoult's law and Henry's law and is recommended for vaccum systems where gas is assumed to behave ideally.

The FD process was modeled using a Gibbs reactor which uses Gibbs free energy minimization with phase splitting to calculate the chemical equilibrium between any number of solid components and the fluid phases. The amount of sublimated water was calculated using a UDF that was developed using the results of İzli [14]. Accordingly, the Two Term model (as shown in Equation (1)) that best described the FD behavior was used for the freeze-dryer simulation.

$$
M R=a_{F D} \exp \left(-k_{0} t\right)+b_{F D} \exp \left(-k_{1} t\right)
$$

where $M R$ is the moisture ratio $\left(M_{t} / M_{0}\right), M_{t}$ represents the moisture at a specific time, $t$ (g water/g dry solid); $M_{0}$ represents the initial moisture content (g water/g dry solid); $k_{0}$ and $k_{1}$ are the drying constants with values $0.002291 \mathrm{~min}^{-1}$ and $0.4768 \mathrm{~min}^{-1}$, respectively; $a_{F D}$ and $b_{F D}$ are FD coefficients with values 0.835 and 0.4768 , respectively. These values were experimentally estimated using various thin-layer drying models for the freeze-drying of dates [14].

For SCE stage modeling, the frozen dates were demonstrated as a mixture of specific components to simulate the extraction process and evaluate the exact yield of these components from the overall fruit matrix. Among the various represented components, glucose and fructose were highlighted as the targeted entities for the extraction by $\mathrm{Sc}-\mathrm{CO}_{2}$. The non-polar portion of the date fruit matrix was represented by fatty acids such as linoleic, palmitic, and oleic acids. The non-extractable material of the biomatrix was represented as cellulose due to its negligible solubility in Sc- $\mathrm{CO}_{2}$ [12]. The phase equilibrium behavior of the glucose-fructose, $\mathrm{Sc}-\mathrm{CO}_{2}$, and water mixture was thermodynamically developed. The process simulation was based on the concept of stages in the extraction. Each stage was assumed as a component separator module at fixed temperature and pressure. The Soave-Redlich-Kwong (SRK) equation of state was used to calculate the thermodynamic properties. The SRK model is suitable for high-temperature and high-pressure extractions, such as supercritical conditioning [24]. Separation unit modules were used to manipulate 
the separation process of $\mathrm{CO}_{2}$-water-glucose-fructose based on the solubility values at a given temperature and pressure. The separation was based on an empirical solubility equation (Equation (2)) proposed by Stahl and Schilz that was fed to manipulator block modules [25].

$$
\log y_{\mathrm{gf}}=A+B P+C P^{2}
$$

where $y_{g f}$ is the solubility of the glucose/fructose in the $\mathrm{Sc}-\mathrm{CO}_{2}(\mathrm{~mol}$ solute $/ \mathrm{mol} \mathrm{CO} 2) ; P$ is the total pressure of the system (bar); and $A, B, C$, are the empirical constants with values $-4.3855,-6.2459 \times 10^{-3}$, and $2.0307 \times 10^{-5}$ for glucose, and $4.5455,-1.2617 \times 10^{-3}$, and $1.1561 \times 10^{-5}$ for fructose, respectively [25]. The solubilities of glucose and fructose in water were calculated according to the work of Saldaña et al., [26]. Additionally, Chrastil's equation [27] was used to model the solubility of the palmitic, oleic, and linoleic acids into $\mathrm{Sc}-\mathrm{CO}_{2}$. Equation (3) presents this model, which is based on the formation of acid-complex upon association of the solute and solvent molecules.

$$
\ln S=k \times \ln \rho_{s}+\frac{a}{T}+b
$$

where $S$ is the solubility of the solute in the supercritical solvent $(\mathrm{g} / \mathrm{L}) ; \rho_{\mathcal{S}}$ is the density of the pure solvent (g/L); and $k, a$, and $b$ are empirical constants. Further, the solubility of water in $\mathrm{CO}_{2}$ was obtained through regression of experimental literature data [28] and is represented by Equation (4).

$S_{w}=\left(1.66 \times 10^{-9}\right)+\left(7.36 \times 10^{-8} \times T\right)+\left(4.54 \times 10^{-8} P\right)+\left(1.22 \times 10^{-6} \times P \times T\right)$

where $S_{w}$ is the solubility of water in $\mathrm{CO}_{2}\left(\mathrm{~kg} \mathrm{H}_{2} \mathrm{O} / \mathrm{kg} \mathrm{CO}_{2}\right)$, and $T$ is the temperature $\left({ }^{\circ} \mathrm{C}\right)$.

Modeling and simulation of the SD stage were performed through the built-in spraydryer unit block model available in Aspen Plus. The necessary parameters for the spraydryer model were specified for the drying process based on the IDEAL property method [29]. The properties for water, air, glucose, and fructose were defined with the conventional values available in the Aspen database. The properties of GA were explicitly included in the software. A rotary atomizer was chosen and modeled with a wheel diameter of $10 \mathrm{~cm}$, four droplet intervals, four $30 \mathrm{~mm}$ blades, and a wheel speed of 18,000 rpm [19]. The characteristic droplet size distribution and nozzle exit velocity were calculated based on the geometry of the nozzle. The median droplet size $\left(d_{50}\right.$, in $\left.\mu \mathrm{m}\right)$ was calculated according to the model (Equation (5)) described by Masters [30].

$$
d_{50}=\frac{K \times \dot{m}_{l i q}^{p}}{N^{q} \times D_{R}^{r} \times(n h)^{s}} \times 10^{4}
$$

where $n$ is the number of blades; $m_{\text {liq }}$ is the mass flow rate of the feed $(\mathrm{kg} / \mathrm{h}) ; N$ is the rotational speed $(\mathrm{rpm}) ; D_{R}$ is the diameter of the atomizer $(\mathrm{m})$; and $h$ is the height of the vanes $(m)$. The constant $K$ and exponents $p, q, r, s$ were determined from the correlations for the vane liquid loading [30]. Subsequently, the mass flow ratio/vane $\left(M_{S}\right)$ to the height of the vanes was determined as $3587.1 \mathrm{~kg} / \mathrm{h} \mathrm{m}$. The validity limits were expressed in terms of the speed of the circumference of the disc $(U)$ using Equation (6).

$$
U=\pi \times \frac{N}{60} \times D_{R}
$$

Thus, the speed of the circumference of the disc was evaluated as $94.25 \mathrm{~m} / \mathrm{s}$. As the values of the $M_{s}$ and $U$ values were in the same category, the design was considerably adequate according to the validity table [30]. The values of the constants and exponents were obtained from the same category. Based on these calculations and validations, the median droplet size $\left(d_{50}\right)$ was estimated as $50.3 \mu \mathrm{m}$. Additionally, the critical moisture content for the drying process was evaluated as $2.67 \mathrm{~kg}$ water $/ \mathrm{kg}$ dry solid (Equation (1)). The equilibrium moisture content was taken as $0.03 \mathrm{~kg}$ water $/ \mathrm{kg}$ dry solid. 
Table 1 summarizes the values for various parameters used for the simulation of each stage. The sensitivity analysis tool of the software was used to study the effect of different critical parameters on the final extracted amount of glucose and fructose.

Table 1. Temperature and pressure of each unit block used in the simulation model.

\begin{tabular}{|c|c|c|}
\hline Unit & Temperature $\left({ }^{\circ} \mathrm{C}\right)$ & Pressure (bar) \\
\hline FREEZER & -42.0 & 1.01325 \\
\hline VACUUM & -42.0 & 0.00048 \\
\hline FRDRY & 20.0 & 0.0001 \\
\hline SEP & 20.0 & 0.0001 \\
\hline FINAL & 20.0 & 1.01325 \\
\hline COMP1 & 783.9 & 308 \\
\hline HEAT1 & 90.0 & 308 \\
\hline PUMP & 40.5 & 308 \\
\hline HEAT2 & 82.0 & 308 \\
\hline MIX1 & 65.0 & 308 \\
\hline EXTRACTO & 65.0 & 308 \\
\hline CO2OUTEX & 65.0 & 308 \\
\hline V1 VALVE & 31.3 & 72 \\
\hline HEAT3 & 32.0 & 1 \\
\hline CO2DENS & 32.0 & 1 \\
\hline MIX2 & 18.2 & 1 \\
\hline SEPARAT & 18.2 & 1 \\
\hline FINALSEP & 18.2 & 1 \\
\hline MIX & 20.0 & 1 \\
\hline AIRHEAT & 150.0 & 1 \\
\hline DRYER & 150.0 & 1 \\
\hline
\end{tabular}

\section{Results and Discussions}

Steady-state modeling and simulation of the IDSPP were conducted successfully using Aspen-Plus Software. Each sub-process was modeled and simulated separately. In addition, sensitivity analysis was performed for each block to identify the optimum operating conditions of the critical parameters for the respective stage.

\subsection{Freeze-Drying}

In the FD method, the biological qualities of the components, flavors, and colors of the food are usually preserved well [31]. For the analysis of IDSPP, vacuum-based FD was considered for the effective removal of moisture at a minimal drying time. The FD model accounted for the phase changes and water vapor diffusion within the date pulp. Modeling for the non-condensable species was accounted through the species transport model [32]. Technically, the feed sample was categorized into four layers, namely frozen front, vapor-ice interface, dry zone, and gas phase. A source term was used to adjust the distribution of gas-phase species due to water vapor generation [33].

Figure 2 depicts the process flow diagram of the FD process. Based on the simulation results, it was observed that the moisture content of the date pulp was reduced from $19.62 \%$ to $0.26 \%$, calculated on a dry weight basis. The mass density of the freeze-dried dates was estimated as $1,639.05 \mathrm{~kg} / \mathrm{m}^{3}$. This relatively low-density value of the freeze-dried date pulp signified higher porosity and thus a potential for improved cell rupture in the SCE stage [32]. Further, sensitivity analysis was performed by varying the temperature and pressure for the FD to examine the effect on the moisture content and duty consumption. The results for the optimization studies of FD are displayed in Figure S2 (Supplementary Materials). A minimum heat duty of $13.23 \mathrm{~kW}$ at a temperature of $-42{ }^{\circ} \mathrm{C}$ and pressure of $0.0001 \mathrm{bar}$ was computed for the FD required for maximum moisture removal. 


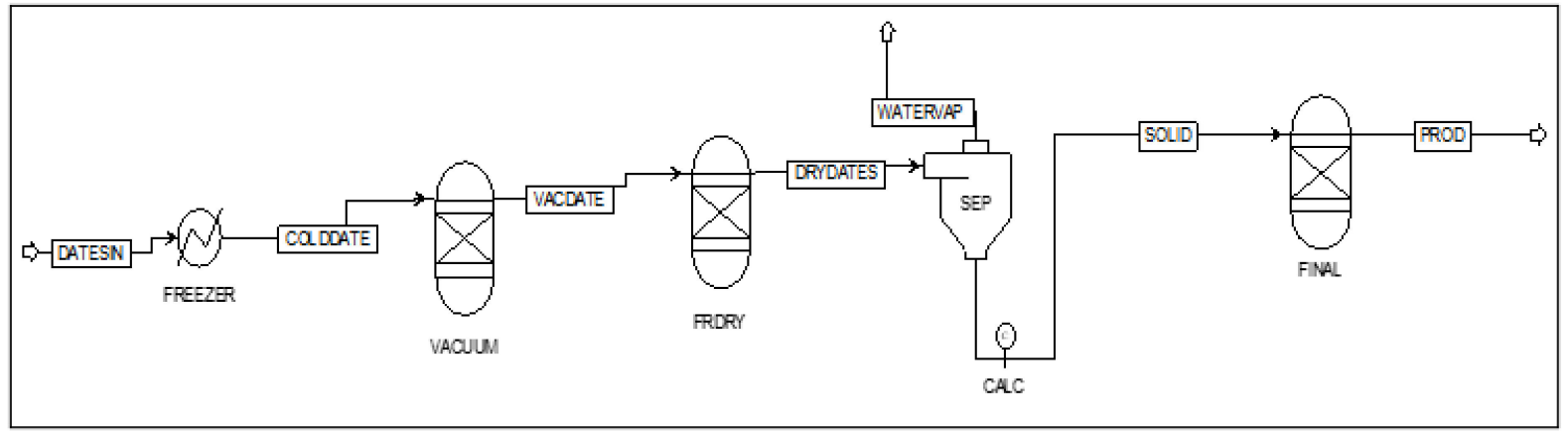

Figure 2. Freeze-drying process flow diagram.

\subsection{Supercritical Extraction}

An Aspen flowsheet for the SCE process is illustrated in Figure 3. For the proper design of the SCE stage, it was essential to employ appropriate mathematical representations. The SCE stage involved extraction from various solid natural matrices that were thermodynamically represented through solubility control, external mass transfer control, and/or internal mass transfer conventional models. Notably, three manipulators were used in the modeling of the SCE stage. The first one, "EXTRCALC" was used to estimate the quantity of the analytes to be extracted by the $\mathrm{Sc}-\mathrm{CO}_{2} /$ water solvent system based on the UDF patched to the software. The UDF contained the necessary data and equations for the solubility behavior of glucose, fructose, and other essential components of date fruit into the solvent mixture. The second one, "CO2OUTCA" calculated the amount of $\mathrm{CO}_{2}$ lost due to the opening of the extraction cell to fix the overall mass balance of the system. The third manipulator, "SEPARATO" was used to estimate the extracted mass lost with the exhaust stream of $\mathrm{CO}_{2}$ gas.

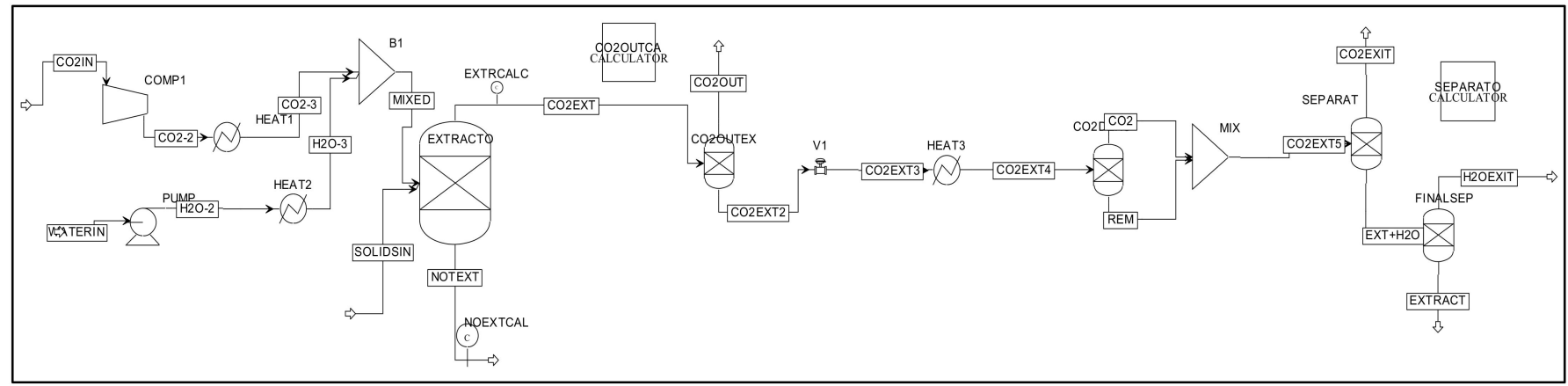

Figure 3. Aspen Plus Supercritical Extraction process flow diagram.

\subsubsection{Operating Pressure}

The extraction pressure of the SCE process is an important parameter that impacts the overall extraction efficiency [34]. Figure 4 shows the pressure effects on the extraction of reducing sugars from the freeze-dried date pulp. Simulation studies revealed that the extraction pressure had varying effects on the recovery of glucose and fructose sugars. For fructose sugar, the recovery efficiency decreased with incremental values in the operating pressure (Figure 4a). On the contrary, the extraction yield increased for glucose sugar with an increase in the operating pressure (Figure $4 \mathrm{~b}$ ). This opposing behavior can be ascribed to the different signs of the empirical coefficients in Equation (2) for glucose and fructose solubility in $\mathrm{Sc}_{-}-\mathrm{CO}_{2}$. Consequently, the trade-off optimization tool of Aspen software was utilized to estimate the optimum pressure required for the maximum extraction of the total reducing sugars. Results showed a maximum product flow (glucose + fructose) of $73.70 \mathrm{~kg} / \mathrm{h}$ was achieved at an operating pressure of $308 \mathrm{bar}$. 

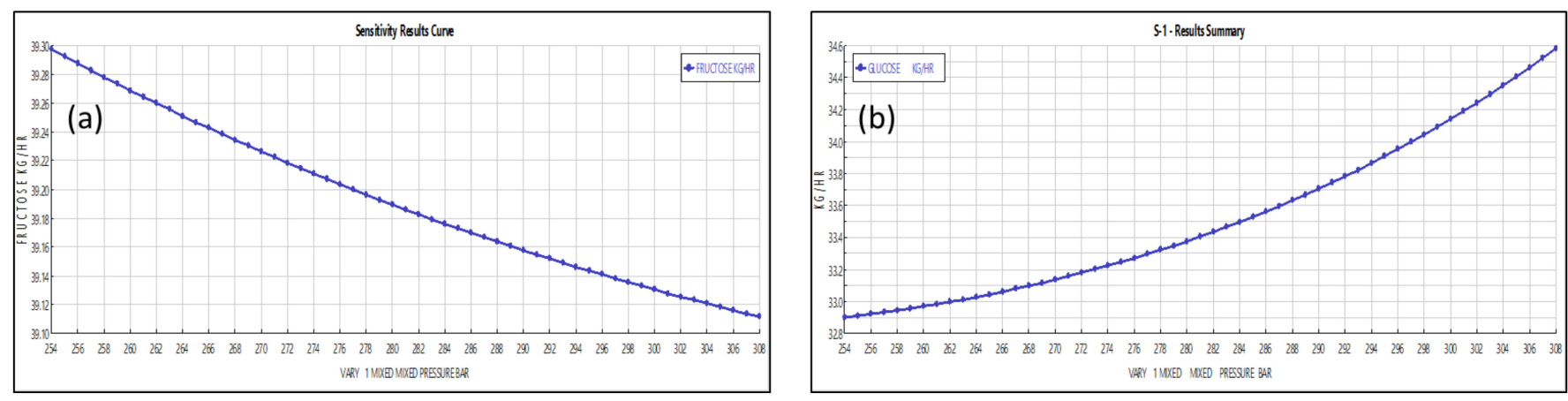

Figure 4. Effect of operating pressure on recovery of fruit sugars-(a) Fructose and (b) Glucose.

\subsubsection{Extraction Temperature}

Similar to pressure, the operating temperature of the SCE process is an imperative parameter that influences the efficiency of the separation process. Simulation studies showed that an increase in the extraction temperature had no significant effects on the recovery of reducing sugars from the fruit pulp. This insignificant temperature effect was anticipated as the solubility equation (Equation (2)) for the monosaccharide sugar molecules into $\mathrm{Sc}-\mathrm{CO}_{2}$ did not involve any temperature effects. However, the extraction of non-polar analytes such as linoleic acid, palmitic acid, and oleic acid by the solvent showed a significant increase with temperature for $\mathrm{T}>70^{\circ} \mathrm{C}$ (Figure S3, Supplementary Materials). The increase in the temperature enhanced the kinetic energy of the $\mathrm{Sc}-\mathrm{CO}_{2}$ fluid, which in turn improved the solvent diffusion and bioactive compound recovery [35]. However, it is worthy of specifying that higher extraction temperatures would cause the thermal degradation of the recovered sugar molecules, reducing the overall yield [36]. Based on the simulation results, an extraction temperature of $65^{\circ} \mathrm{C}$ was recommended for the SCE stage.

\subsubsection{Solvent Flow Rate and Composition}

Results on the sensitivity analysis for the solvent:co-solvent ratio showed that a cosolvent concentration of $6.77 \mathrm{wt} . \%$ produced the maximum recovery of reducing sugars from the date pulp biomatrix. The simulation run resulted in an overall extraction yield of $99.1 \%$ for the reducing sugars with flow rates of $34.14 \mathrm{~kg} / \mathrm{h}$ and $39.13 \mathrm{~kg} / \mathrm{h}$ for glucose and fructose, respectively. Moreover, the sensitivity analysis showed that the total extracted quantity of glucose and fructose increased with the flow rate of $\mathrm{Sc}-\mathrm{CO}_{2}$, as shown in Figure 5. Almost all of the reducing sugars were extracted into the solvent system for an $\mathrm{Sc}-\mathrm{CO}_{2}$ flow rate of $31,000 \mathrm{~kg} / \mathrm{h}$. Further increases in the $\mathrm{Sc}-\mathrm{CO}_{2}$ flow rate had no significant effects on the sugar extraction. This quantity of $\mathrm{Sc}-\mathrm{CO}_{2}$ defines the solvent limit required for the maximum removal of targeted sugar components from the date palm fruit. Based on the optimization studies for the solvent:co-solvent ratio and the $\mathrm{Sc}-\mathrm{CO}_{2}$ flow rate, the optimum flow rate of water was estimated as $2100 \mathrm{~kg} / \mathrm{h}$ for the maximum recovery of glucose and fructose components. Figure 6 shows the effect of the water flow rate on the extraction of reducing sugars from the fruit biomatrix. Similar to $\mathrm{Sc}-\mathrm{CO}_{2}$, the extraction yield increased with incremental levels of water flow rate. The improvement in the extraction of monosaccharides was due to the enhanced permeability and polarity of water molecules at the extraction conditions.

In general, the mass transfer mechanism for the recovery of plant bioactive compounds using supercritical technology involves four major steps [37]. Firstly, the analytes are desorbed from the biomatrix into the solvent film. Second, the analytes diffuse into the solvent, while in the third, the analytes dissolve into the solvent. The final step involves the bulk mass transfer of the solvent from the biomatrix to the external. Based on this mechanism, the increase in the extract yield with the flow rate of the solvent system signified that the external film transfer diffusion (second step) quantified by a diffusion coefficient, and the dissolution potential of sugars into the $\mathrm{Sc}-\mathrm{CO}_{2} /$ water system (third 
step) quantified by a partitioning coefficient, played the limiting roles for the recovery of the targeted analytes [38].

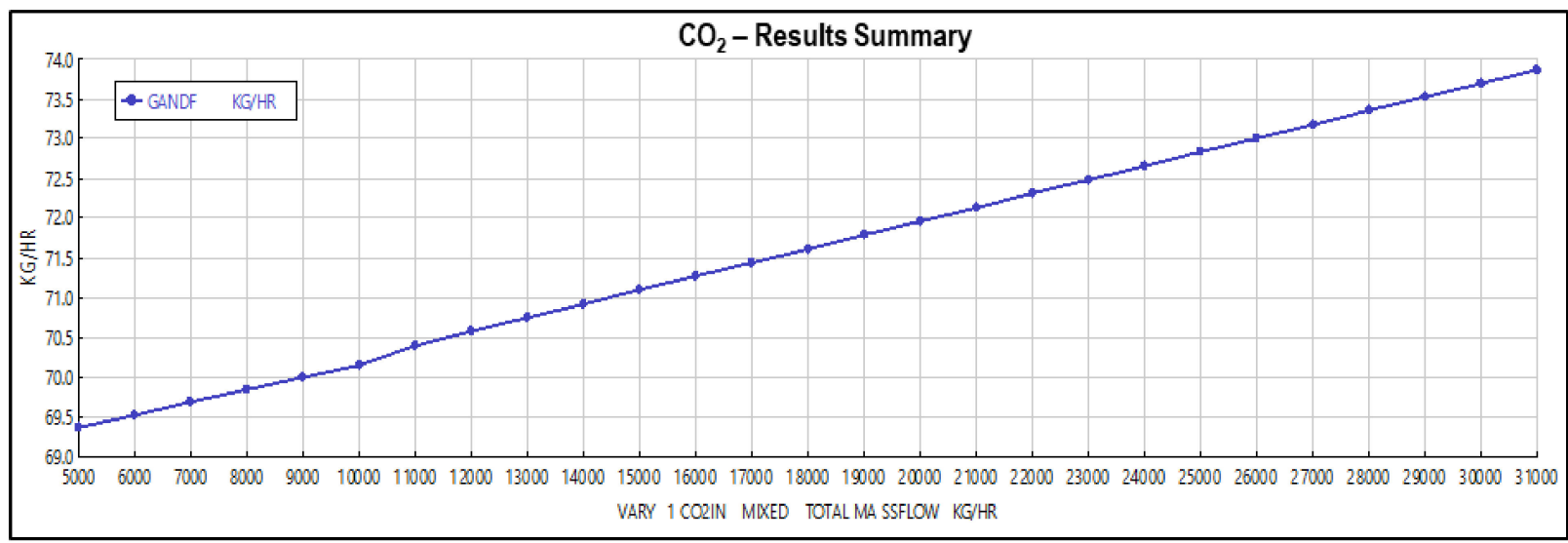

Figure 5. Effect of $\mathrm{Sc}-\mathrm{CO}_{2}$ flow rate on glucose and fructose recovery from date pulp.

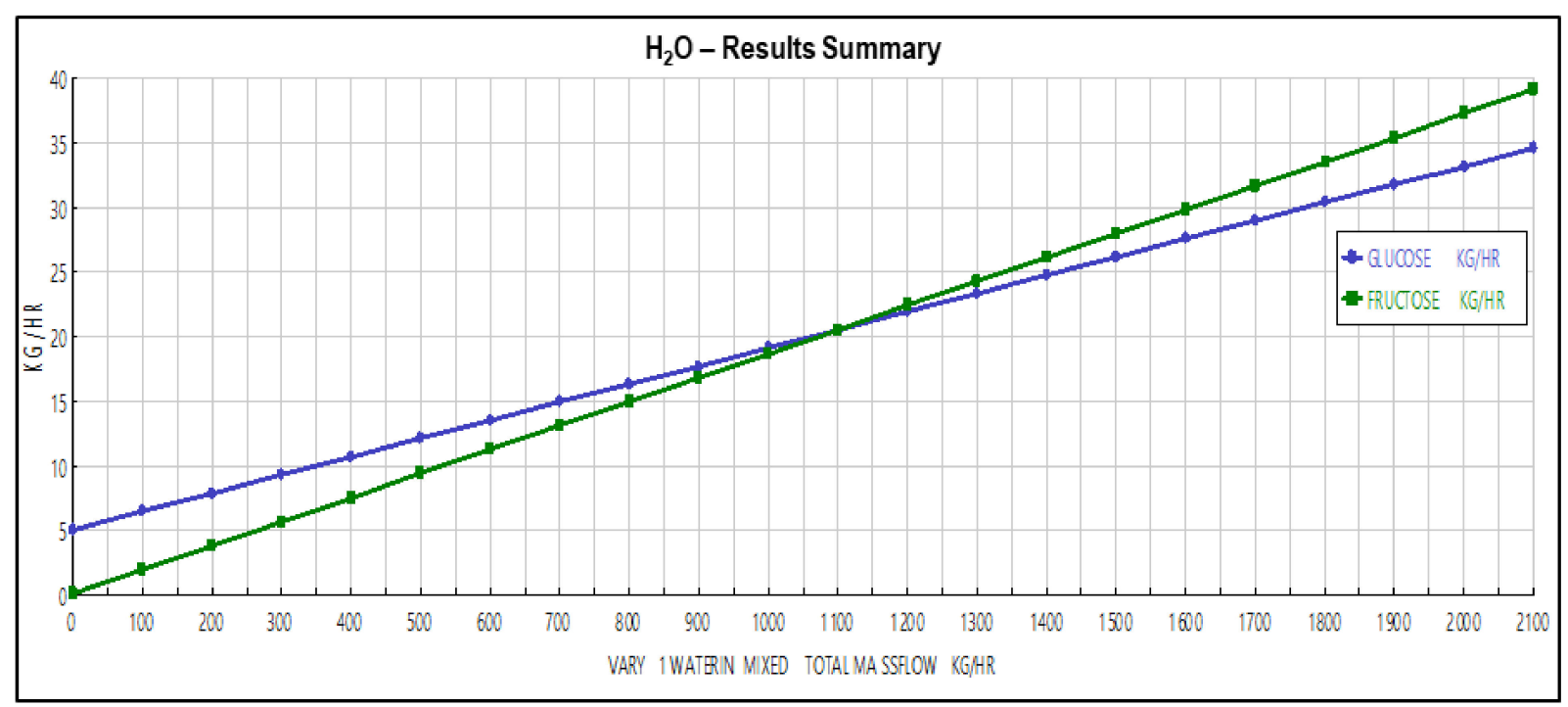

Figure 6. Effect of water flow rate on glucose and fructose recovery from date pulp.

\subsection{Spray-Drying}

In general, beneficial features such as high drying rate, shorter drying time, and broad working temperature make SD an ideal choice for drying of food products to powder form [32]. The complicated three-dimensional nature of spray-dryers often makes it difficult to describe their exact behavior using empirical models. In this work, Aspen's builtin simulator was used to characterize the SD process of the SCE extract (glucose and fructose solution) mixed with GA as the carrying agent. The model employed an EulerianLagrangian approach to compute the particle motion paths, and heat and mass transfer phenomena occurring between the drying medium and the feed particles [32]. The choice of GA was to overcome the stickiness effect and increase the glass transition temperature of the mixture. Based on the previously reported experimental studies of SD for date fruit powder, the mass ratio of GA to SCE extract was fixed as 0.4 [18]. Figure 7 represents the process flow diagram for the SD stage of the IDSPP technology. 


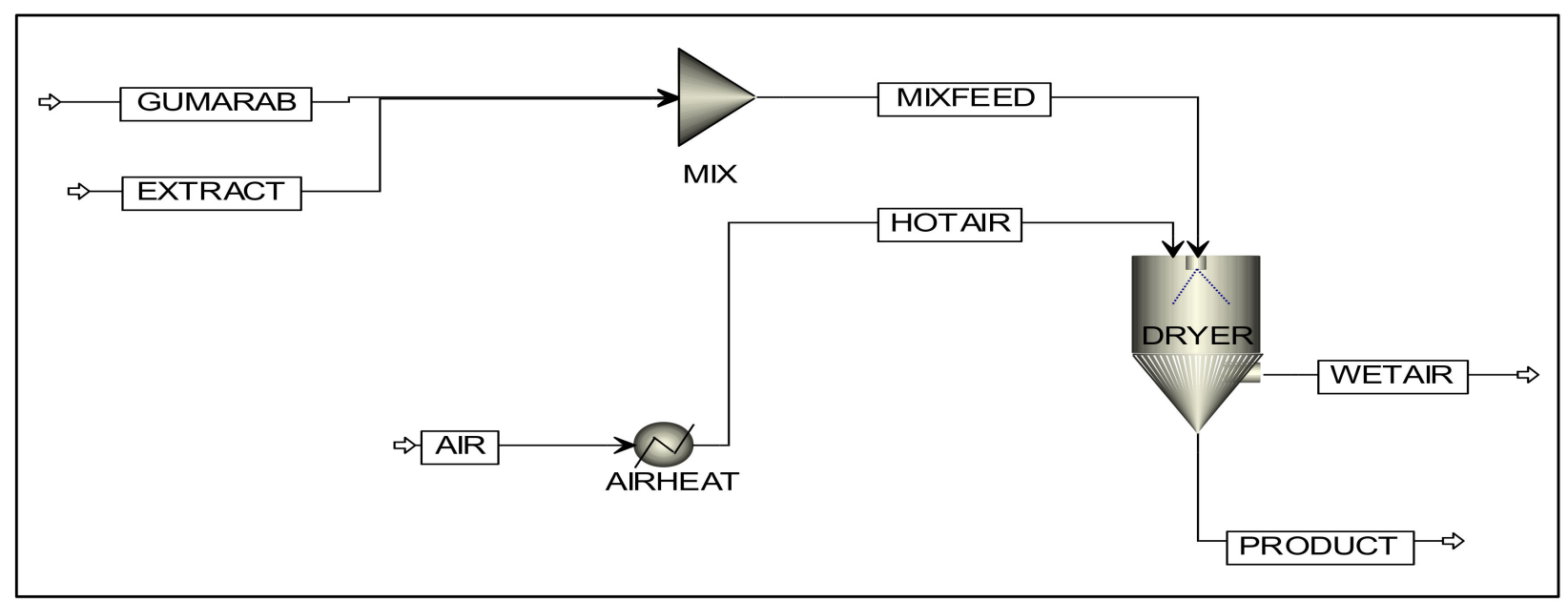

Figure 7. Aspen Plus Spray Drying process flow diagram.

Sensitivity analysis of the SD stage involved the study of the effect of different parameters on the final moisture content of the sugar powder. Results showed that the final moisture content of the powdered product decreased with an increase in the mass flow rate of the drying air (Figure S4, Supplementary Materials). Complete removal of excess moisture was observed at an airflow rate of $8000 \mathrm{~kg} / \mathrm{h}$ resulting in powdered sugar with the equilibrium moisture content. High flow rates of the drying air reduced the droplet size due to their improved atomizing effect. This resulted in a finer particle size of the product with a larger surface area that facilitated the rapid and higher drying rate of the product with complete removal of moisture [30]. It is worth specifying that the blank simulation without GA addition resulted in low drying efficiency. This can be attributed to the possible stickiness of the feed extract, as reported in several other related experimental works [39].

Figure 8a shows the effect of the inlet air temperature on the moisture removal from the feed solution for the powdered product formation. It was observed that an increase in the air temperature resulted in improved moisture elimination. This was clearly due to the improved heat and mass transfer processes between the air and feed particles owing to the greater driving force for moisture evaporation [40]. Moreover, higher operating temperatures would eliminate insufficient drying of the particles, thereby reducing the probability of semi-wet/sticky solids formation that would typically stick to the wall and thus result in higher yield [39]. Simulation results showed the attainment of equilibrium moisture content at a minimum air inlet temperature of $150{ }^{\circ} \mathrm{C}$ for the formation of dry powdered products of date sugar. Further, the results for the dependency of product moisture content on the feed flow rate are shown in Figure 8b. It was evident that lower feed flow rates resulted in a relatively drier product than higher flow rates. In the SD stage, a higher feed rate may result in slower heat and mass transfer processes. An increase in feed flow rate reduces the contact time between the drying medium and the atomized particles leading to low heat transfer rates resulting in low moisture removal. In general, feed flow rate not only affects the moisture content and yield of the product but also significantly influences the product solubility and water activity [41]. Based on the simulation results, a feed flow rate of $435 \mathrm{~kg} / \mathrm{h}$ was recommended for the SD stage of the IDSPP.

\subsection{Product Solubility}

Product solubility is a critical benchmark for food products, especially food-grade sugars, to be used as an additive in food and beverages. In general, several parameters of the product, such as composition, water activity, morphology, equilibrium moisture content, etc., affect the product solubility [42]. The solubility of the product (glucose and fructose mixture) in an aqueous medium was simulated over a temperature range from 0 to $100{ }^{\circ} \mathrm{C}$ and at a pressure of 1 bar based on the UNIQUAC (universal quasichemical) thermodynamic model. The solid-liquid phase equilibrium of the powdered date sugar 
in pure water was simulated using activity coefficients [43]. The solubility of the sugar product at a temperature of $25^{\circ} \mathrm{C}$ and 1 bar was estimated as $0.89 \mathrm{~g} / \mathrm{g}$ water. Comparing this value with the solubility of the table sugar $(2.1 \mathrm{~g} / \mathrm{g}$ water), it was observed that sucrose (in table sugar) had a higher solubility than the extracted date sugar. However, it is expected that experimental validation would result in higher solubility of the date sugar powder due to the good emulsification properties and high solubility of GA in aqueous solutions [22]. Figure 9 depicts the PSD for the final powder product obtained for the optimal operating conditions of the SD step. The mean particle size and density were estimated as $504 \mu \mathrm{m}$ and $0.0023 \mathrm{~kg} / \mathrm{m}^{3}$, respectively, demonstrating the presence of significant levels of bioactive compounds in the product [42]. In addition, powders obtained using lower drying temperatures tend to possess a high percentage of smaller particles in the micro-range.
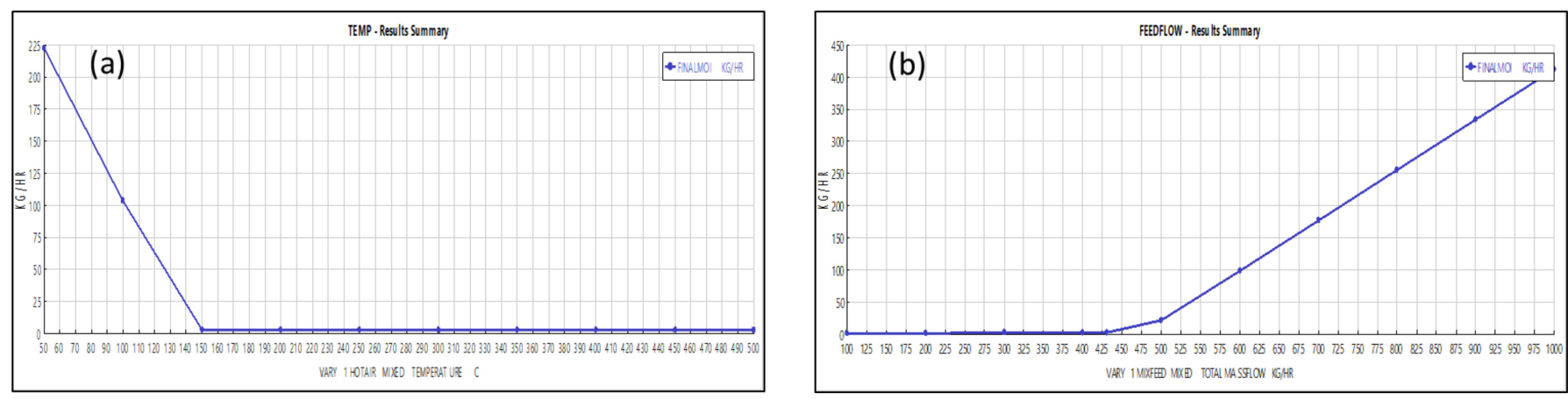

Figure 8. Effect of (a) inlet air temperature and (b) feed flow rate on the moisture content of the date sugar powder product.

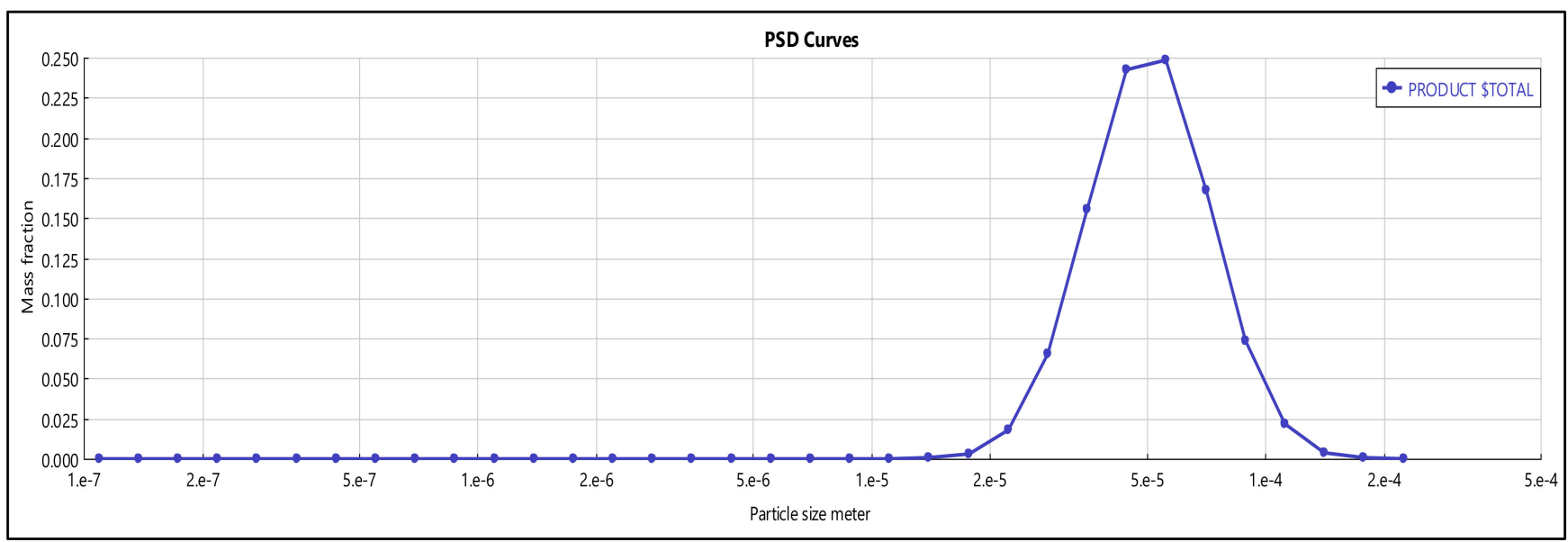

Figure 9. Particle size distribution of the spray-dried date sugar powder.

Experimental validation of IDSPP technology, with extensive analysis of extracts (including other vital analytes such as fibers, minerals, amino acids, etc.), determination of the extraction equilibrium and kinetics [44-47], and establishment of the necessary economics for production along with regulatory waste management approaches [48-50] would potentially realize effective production of date sugar that could ideally replace refined sugar.

\section{Conclusions}

In summary, this work conceptualized a novel IDSPP technology comprising of three main stages, namely freeze-drying, supercritical extraction, and spray-drying to process $100 \mathrm{~kg} / \mathrm{h}$ of date fruit pulp to produce a soluble date sugar product. Stage-wise modeling 
and simulation studies were performed using Aspen Plus software with the sensitivity analysis to identify the optimum values of critical parameters for each stage. Freeze-drying studies revealed a minimum duty requirement of $13.23 \mathrm{~kW}$ at a temperature of $-42{ }^{\circ} \mathrm{C}$ and pressure of 0.0001 bar to reduce the moisture content of the fruit pulp from $19.62 \%$ to $0.26 \%$. The $\mathrm{Sc}-\mathrm{CO}_{2}$ assisted extraction resulted in a total sugar recovery of $99.1 \%$ with flow rates of $34.14 \mathrm{~kg} / \mathrm{h}$ and $39.13 \mathrm{~kg} / \mathrm{h}$ for glucose and fructose sugars, respectively. Optimization studies showed that a pressure of 308 bar, temperature of $65{ }^{\circ} \mathrm{C}, \mathrm{Sc}-\mathrm{CO}_{2}$ flow rate of $31,000 \mathrm{~kg} / \mathrm{h}$, and $\mathrm{Sc}-\mathrm{CO}_{2}$ : water ratio of 0.07 resulted in the maximum extraction efficiency. Further, spray-drying simulation of the date extract into a powdered product using Gum Arabic as the carrier agent showed a mean particle size of $50.4 \mu \mathrm{m}$ for the date sugar powder with a solubility of $0.89 \mathrm{~g} / \mathrm{g}$ water (at 25 and 1 bar) and density of $0.0023 \mathrm{~kg} / \mathrm{m}^{3}$. Sensitivity analysis revealed that the extraction pressure and solvent flow rates were the significant parameters for the extraction step while operating temperature had no salient effects on the recovery of the sugar. For the spray-drying process, drying air flow rate and its inlet temperature had positive effects, while feed flow rate negatively impacted moisture removal. Results showed that a mass flow rate of $8000 \mathrm{~kg} / \mathrm{h}$ and an inlet temperature of $150{ }^{\circ} \mathrm{C}$ for the drying air was optimal to dry a feed stream mixture of date extract and Gum Arabic flowing at $435 \mathrm{~kg} / \mathrm{h}$ containing $40 \mathrm{wt} . \%$ of Gum Arabic. Thus, this work confirmed the technical feasibility of IDSPP for the production of soluble date sugar powder and provided the necessary data with optimum operating conditions required for the process. Experimental validations and detailed characterizations of the product are further required to realize the outcomes of this study.

Supplementary Materials: The following supporting information can be downloaded at: https: / /www.mdpi.com/article/10.3390/pr10020257/s1, Figure S1: Chemical structure of Gum Arabic, Figure S2: Sensitivity analysis for FD: Temperature and pressure effects on the final moisture content and the net heat duty, Figure S3: Effect of temperature on the recovery of non-polar analytes of date fruit pulp, Figure S4: Effect of drying air flow rate on the moisture content of the date sugar powder product, Table S1: Properties of Gum Arabic used for the ASPEN simulation.

Author Contributions: Conceptualization, R.K. and F.B.; Data curation, H.B. and N.A.; Formal analysis, H.B., R.K. and S.W.H.; Investigation, H.B.; Methodology, R.K. and M.A.-Z.; Project administration, F.B.; Resources, S.W.H. and H.T.; Software, H.B. and R.K.; Supervision, F.B.; Validation, M.A.-Z., S.W.H., S.Y.A. and F.B.; Visualization, H.T.; Writing—original draft, H.B. and R.K.; Writing—review \& editing, M.A.-Z., S.Y.A., N.A. and F.B. All authors have read and agreed to the published version of the manuscript.

Funding: This work was entirely funded and supported by the project grant CIRA-2019-028 under the Competitive Internal Research Award scheme of Khalifa University, UAE. The article processing charges were funded by grant RSP-2021/35, King Saud University, Riyadh, Saudi Arabia.

Institutional Review Board Statement: Not applicable.

Informed Consent Statement: Not applicable.

Data Availability Statement: Not applicable.

Acknowledgments: This work was entirely funded and supported by the project grant CIRA-2019028 under the Competitive Internal Research Award scheme of Khalifa University, UAE. This project was supported by the Researchers Supporting Project Number (RSP-2021/35), King Saud University, Riyadh, Saudi Arabia.

Conflicts of Interest: The authors declare no conflict of interest. 


\section{Nomenclature}

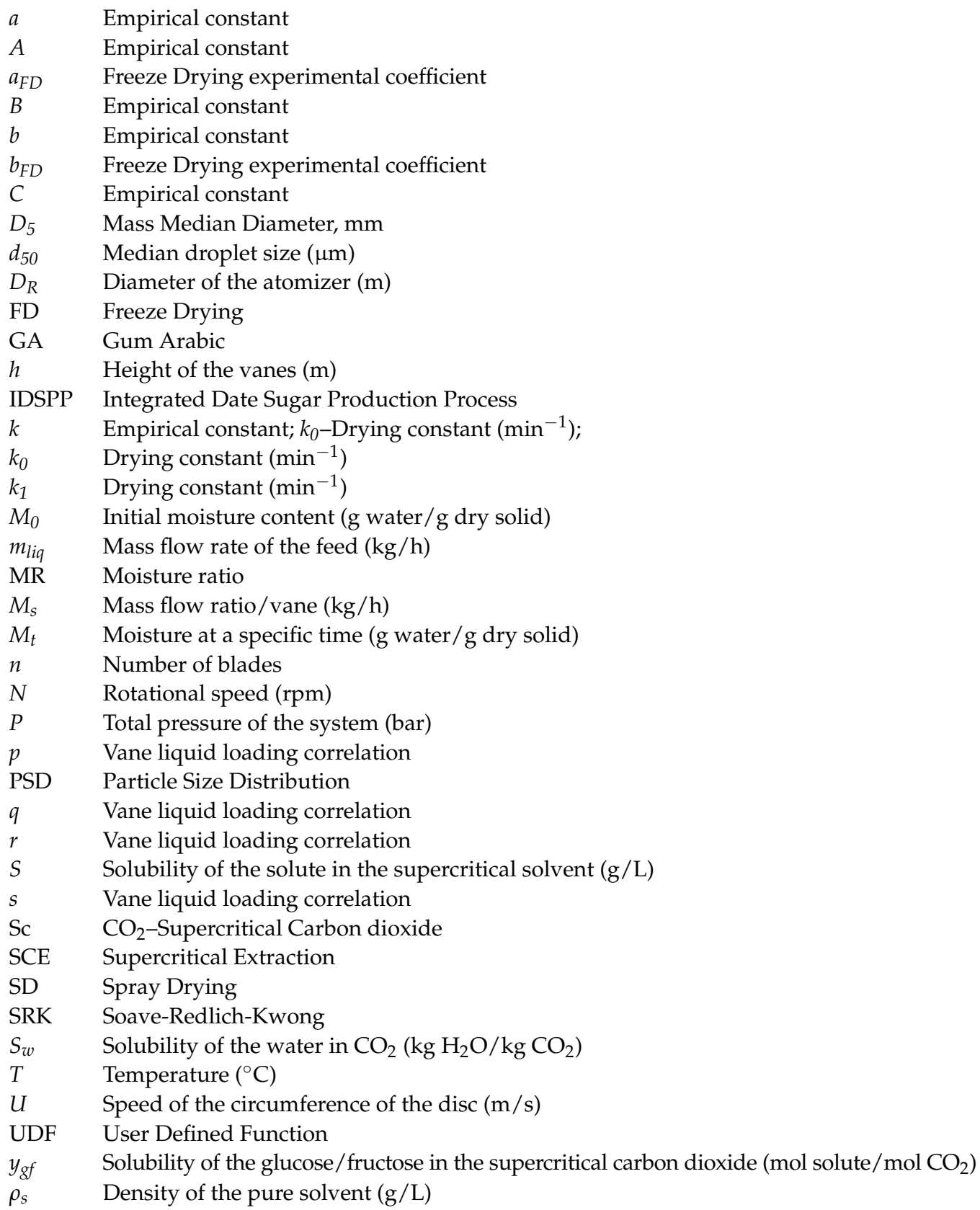

\section{References}

1. Voora, V.; Bermúdez, S.; Larrea, C. Global Market Report: Sugar; International Institute for Sustainable Development: Geneva, Switzerland, 2020.

2. Rambabu, K.; Bharath, G.; Hai, A.; Banat, F.; Hasan, S.W.; Taher, H.; Zaid, H.F.M. Nutritional Quality and Physico-Chemical Characteristics of Selected Date Fruit Varieties of the United Arab Emirates. Processes 2020, 8, 256. [CrossRef]

3. Ahmed, I.A.; Ahmed, A.W.K.; Robinson, R.K. Chemical composition of date varieties as influenced by the stage of ripening. Food Chem. 1995, 54, 305-309. [CrossRef]

4. Alharbi, K.L.; Raman, J.; Shin, H.-J. Date Fruit and Seed in Nutricosmetics. Cosmetics 2021, 8, 59. [CrossRef]

5. Ameer, K.; Shahbaz, H.M.; Kwon, J.H. Green Extraction Methods for Polyphenols from Plant Matrices and Their Byproducts: A Review. Compr. Rev. Food Sci. Food Saf. 2017, 16, 295-315. [CrossRef] [PubMed]

6. Rambabu, K.; Edathil, A.A.; Nirmala, G.S.; Hasan, S.W.; Yousef, A.F.; Show, P.L.; Banat, F. Date-fruit syrup waste extract as a natural additive for soap production with enhanced antioxidant and antibacterial activity. Environ. Technol. Innov. 2020, 20, 101153. [CrossRef] 
7. Vallejo-Domínguez, D.; Rubio-Rosas, E.; Aguila-Almanza, E.; Hernández-Cocoletzi, H.; Ramos-Cassellis, M.E.; Luna-Guevara, M.L.; Rambabu, K.; Manickam, S.; Munawaroh, H.S.H.; Show, P.L. Ultrasound in the deproteinization process for chitin and chitosan production. Ultrason. Sonochem. 2021, 72, 105417. [CrossRef] [PubMed]

8. Arumugham, T.; Rambabu, K.; Hasan, S.W.; Show, P.L.; Rinklebe, J.; Banat, F. Supercritical carbon dioxide extraction of plant phytochemicals for biological and environmental applications-A review. Chemosphere 2021, 271, 129525. [CrossRef] [PubMed]

9. Al-Suod, H.; Ratiu, I.A.; Krakowska-Sieprawska, A.; Lahuta, L.; Górecki, R.; Buszewski, B. Supercritical fluid extraction in isolation of cyclitols and sugars from chamomile flowers. J. Sep. Sci. 2019, 42, 3243-3252. [CrossRef] [PubMed]

10. Ratiu, I.-A.; Al-Suod, H.; Ligor, M.; Ligor, T.; Railean-Plugaru, V.; Buszewski, B. Complex investigation of extraction techniques applied for cyclitols and sugars isolation from different species of Solidago genus. Electrophoresis 2018, 39, 1966-1974. [CrossRef]

11. Cavalcanti, R.N.; Albuquerque, C.L.C.; Meireles, M.A.A. Supercritical $\mathrm{CO}_{2}$ extraction of cupuassu butter from defatted seed residue: Experimental data, mathematical modeling and cost of manufacturing. Food Bioprod. Process. 2016, 97, 48-62. [CrossRef]

12. Mirofci, S. A supercritical fluid extraction process to obtain valuable compounds from Eruca sativa leaves. Masters Thesis, University of Padova, Padua, Italy, 2014.

13. Dohrn, R.; Buenz, A.P. Solubility enhancement of carbohydrates in carbon dioxide (Part 1 and 2). Int. Z. Lebensm. 1995, 46, 30-31

14. İZL̇, G. Total phenolics, antioxidant capacity, colour and drying characteristics of date fruit dried with different methods. Food Sci. Technol. 2016, 37, 139-147. [CrossRef]

15. Seerangurayar, T.; Manickavasagan, A.; Al-Ismaili, A.M.; Al-Mulla, Y.A. Effect of carrier agents on flowability and microstructural properties of foam-mat freeze dried date powder. J. Food Eng. 2017, 215, 33-43. [CrossRef]

16. Franceschinis, L.; Salvatori, D.M.; Sosa, N.; Schebor, C. Physical and functional properties of blackberry freeze-and spray-dried powders. Dry. Technol. 2014, 32, 197-207. [CrossRef]

17. Shishehgarha, F.; Makhlouf, J.; Ratti, C. Freeze-drying characteristics of strawberries. Dry. Technol. 2002, 20, 131-145. [CrossRef]

18. Manickavasagan, A.; Thangavel, K.; Dev, S.R.S.; Delfiya, D.S.A.; Nambi, E.; Orsat, V.; Raghavan, G.S.V. Physicochemical characteristics of date powder produced in a pilot-scale spray dryer. Dry. Technol. 2015, 33, 1114-1123. [CrossRef]

19. Minh, N.P.; Vo, T.T.; Tu, T.T.C.; Vi, M.N.T.; Diem, N.T.N.; Thanh, H.T.T. Spray Drying Parameters Affecting to Dried Powder from Palmyra Palm (Borassus flabellifer) Juice. J. Pharm. Sci. Res. 2019, 11, 1382-1387.

20. Anderson, D.M.W. Evidence for the safety of gum arabic (Acacia senegal (L.) Willd.) as a food additive-A brief review. Food Addit. Contam. 1986, 3, 225-230. [CrossRef]

21. Georgetti, S.R.; Casagrande, R.; Souza, C.R.F.; Oliveira, W.P.; Fonseca, M.J.V. Spray drying of the soybean extract: Effects on chemical properties and antioxidant activity. LWT-Food Sci. Technol. 2008, 41, 1521-1527. [CrossRef]

22. Glicksman, M. Gum arabic (Gum acacia). In Food Hydrocolloids; CRC Press: Boca Raton, FL, USA, 2019; pp. 7-29.

23. Rockstraw, D.A. ASPEN Plus in the Chemical Engineering Curriculum: Suitable Course Content and Teaching Methodology. Chem. Eng. Educ. 2005, 39, 68-75.

24. Rostamian, H.; Lotfollahi, M.N. New functionality for energy parameter of Redlich-Kwong equation of state for density calculation of pure carbon dioxide and ethane in liquid, vapor and supercritical phases. Period. Polytech. Chem. Eng. 2016, 60, 93-97. [CrossRef]

25. Stahl, E.; Schilz, W.; Schütz, E.; Willing, E. A quick method for the microanalytical evaluation of the dissolving power of supercritical gases. Angew. Chem. Int. Ed. Engl. 1978, 17, 731-738. [CrossRef]

26. Saldaña, M.D.A.; Alvarez, V.H.; Haldar, A. Solubility and physical properties of sugars in pressurized water. J. Chem. Thermodyn. 2012, 55, 115-123. [CrossRef]

27. Chrastil, J. Solubility of solids and liquids in supercritical gases. J. Phys. Chem. 1982, 86, 3016-3021. [CrossRef]

28. King, A.D., Jr.; Coan, C.R. Solubility of water in compressed carbon dioxide, nitrous oxide, and ethane. Evidence for hydration of carbon dioxide and nitrous oxide in the gas phase. J. Am. Chem. Soc. 1971, 93, 1857-1862. [CrossRef]

29. Petersen, L.N.; Poulsen, N.K.; Niemann, H.H.; Utzen, C.; Jørgensen, J.B. An experimentally validated simulation model for a four-stage spray dryer. J. Process Control 2017, 57, 50-65. [CrossRef]

30. Masters, K. Spray Drying Handbook; Halstead Press: New York, NY, USA, 1985.

31. Nakagawa, K.; Ochiai, T. A mathematical model of multi-dimensional freeze-drying for food products. J. Food Eng. 2015, 161, 55-67. [CrossRef]

32. Malekjani, N.; Jafari, S.M. Simulation of food drying processes by Computational Fluid Dynamics (CFD); recent advances and approaches. Trends Food Sci. Technol. 2018, 78, 206-223. [CrossRef]

33. Li, S.; Stawczyk, J.; Zbicinski, I. CFD model of apple atmospheric freeze drying at low temperature. Dry. Technol. 2007, 25, 1331-1339. [CrossRef]

34. Malaman, F.S.; Moraes, L.A.B.; West, C.; Ferreira, N.J.; Oliveira, A.L. Supercritical fluid extracts from the Brazilian cherry (Eugenia uniflora L.): Relationship between the extracted compounds and the characteristic flavour intensity of the fruit. Food Chem. 2011, 124, 85-92. [CrossRef]

35. Zhang, Q.; Zhao, M.; Xu, Q.; Ren, H.; Yin, J. Enhanced enzymatic hydrolysis of sorghum stalk by supercritical carbon dioxide and ultrasonic pretreatment. Appl. Biochem. Biotechnol. 2019, 188, 101-111. [CrossRef] [PubMed]

36. Oladipupo Kareem, M.; Edathil, A.A.; Rambabu, K.; Bharath, G.; Banat, F.; Nirmala, G.S.S.; Sathiyanarayanan, K. Extraction, characterization and optimization of high quality bio-oil derived from waste date seeds. Chem. Eng. Commun. 2021, 208, 801-811. [CrossRef] 
37. Islam, M.N.; Jo, Y.-T.; Jung, S.-K.; Park, J.-H. Thermodynamic and kinetic study for subcritical water extraction of PAHs. J. Ind. Eng. Chem. 2013, 19, 129-136. [CrossRef]

38. Khajenoori, M.; Asl, A.H.; Hormozi, F. Proposed models for subcritical water extraction of essential oils. Chin. J. Chem. Eng. 2009, 17, 359-365. [CrossRef]

39. Fazaeli, M.; Emam-Djomeh, Z.; Ashtari, A.K.; Omid, M. Effect of spray drying conditions and feed composition on the physical properties of black mulberry juice powder. Food Bioprod. Process. 2012, 90, 667-675. [CrossRef]

40. Rambabu, K.; Muruganandam, L.; Velu, S. CFD simulation for separation of carbon dioxide-methane mixture by pressure swing adsorption. Int. J. Chem. Eng. 2014, 2014, 402756. [CrossRef]

41. Cortés-Rojas, D.F.; Souza, C.R.F.; Oliveira, W.P. Optimization of spray drying conditions for production of Bidens pilosa L. dried extract. Chem. Eng. Res. Des. 2015, 93, 366-376. [CrossRef]

42. Lourenço, S.C.; Moldão-Martins, M.; Alves, V.D. Microencapsulation of pineapple peel extract by spray drying using maltodextrin, inulin, and arabic gum as wall matrices. Foods 2020, 9, 718. [CrossRef]

43. Zhao, H.; Li, J.; Wang, L.; Li, C.; Li, P. Thermodynamic investigation of 1,3,5-trioxane, methyl acrylate, methyl acetate, and water mixtures, in terms of NRTL and UNIQUAC models. Ind. Eng. Chem. Res. 2019, 58, 18378-18386. [CrossRef]

44. Ramu, A.G.; Telmenbayar, L.; Theerthagiri, J.; Yang, D.; Song, M.; Choi, D. Synthesis of a hierarchically structured Fe $\mathrm{O}_{4}-\mathrm{PEI}$ nanocomposite for the highly sensitive electrochemical determination of bisphenol A in real samples. New J. Chem. 2020, 44, 18633-18645. [CrossRef]

45. Theerthagiri, J.; Lee, S.J.; Murthy, A.P.; Madhavan, J.; Choi, M.Y. Fundamental aspects and recent advances in transition metal nitrides as electrocatalysts for hydrogen evolution reaction: A review. Curr. Opin. Solid State Mater. Sci. 2020, $24,100805$. [CrossRef]

46. Madhavan, J.; Theerthagiri, J.; Balaji, D.; Sunitha, S.; Choi, M.Y.; Ashokkumar, M. Hybrid advanced oxidation processes involving ultrasound: An overview. Molecules 2019, 24, 3341. [CrossRef]

47. Senthil, R.A.; Priya, A.; Theerthagiri, J.; Selvi, A.; Nithyadharseni, P.; Madhavan, J. Facile synthesis of $\alpha-\mathrm{Fe}_{2} \mathrm{O}_{3} / \mathrm{WO}_{3}$ composite with an enhanced photocatalytic and photo-electrochemical performance. Ionics 2018, 24, 3673-3684. [CrossRef]

48. Theerthagiri, J.; Senthil, R.A.; Priya, A.; Madhavan, J.; Michael, R.J.V.; Ashokkumar, M. Photocatalytic and photoelectrochemical studies of visible-light active $\alpha-\mathrm{Fe}_{2} \mathrm{O}_{3}-\mathrm{gC}_{3} \mathrm{~N}_{4}$ nanocomposites. Rsc Adv. 2014, 4, 38222-38229. [CrossRef]

49. Theerthagiri, J.; Senthil, R.A.; Senthilkumar, B.; Polu, A.R.; Madhavan, J.; Ashokkumar, M. Recent advances in MoS 2 nanostructured materials for energy and environmental applications-A review. J. Solid State Chem. 2017, 252, 43-71. [CrossRef]

50. Theerthagiri, J.; Salla, S.; Senthil, R.A.; Nithyadharseni, P.; Madankumar, A.; Arunachalam, P.; Maiyalagan, T.; Kim, H.-S. A review on $\mathrm{ZnO}$ nanostructured materials: Energy, environmental and biological applications. Nanotechnology 2019, 30, 392001. [CrossRef] 